\title{
Article \\ Electrochemical Nucleation and Growth Mechanism of Aluminum on AZ31 Magnesium Alloys
}

\author{
Jinling Zhang ${ }^{1,2,3, *}$, Yelei $\mathrm{Li}^{1}{ }^{1}$, Xiaomin Zhang ${ }^{1}$, Yanchong $\mathrm{Yu}^{1}$ and Shebin Wang ${ }^{1,2,3}$ \\ 1 College of Material Science and Engineering, Taiyuan University of Technology, Taiyuan 030024, China; \\ lixiaokui1997@gmail.com (Y.L.); dcxiongij@163.com (X.Z.); yuyanchongtyut@163.com (Y.Y.); \\ shebinwang@163.com (S.W.) \\ 2 Key Laboratory of Interface Science and Engineering in Advanced Materials, Ministry of Education, \\ Taiyuan 030024, China \\ 3 Shanxi Research Center of Advanced Materials Science and Technology, Taiyuan 030024, China \\ * Correspondence: zhjlty@163.com
}

Citation: Zhang, J.; Li, Y.; Zhang, X.; Yu, Y.; Wang, S. Electrochemical

Nucleation and Growth Mechanism of Aluminum on AZ31 Magnesium Alloys. Coatings 2021, 11, 46. https://doi.org/10.3390/ coatings11010046

Received: 3 December 2020 Accepted: 31 December 2020 Published: 5 January 2021

Publisher's Note: MDPI stays neutral with regard to jurisdictional clai$\mathrm{ms}$ in published maps and institutional affiliations.

Copyright: (C) 2021 by the authors. Licensee MDPI, Basel, Switzerland. This article is an open access article distributed under the terms and conditions of the Creative Commons Attribution (CC BY) license (https:// creativecommons.org/licenses/by/ $4.0 /)$.

\begin{abstract}
In this study, the nucleation and growth kinetics behavior of aluminum (Al) were investigated in the Choline-chloride $(\mathrm{ChCl})$-urea deep eutectic solvent (DES) ionic liquids. The studies of cyclic voltammetric and chronoamperometry demonstrated that the electrodeposition process of $\mathrm{Al}$ was controlled by three-dimensional progressive nucleation and instantaneous nucleation. And the growth of nuclei is a diffusion-controlled process. The diffusion coefficient of $\mathrm{Al}$ ions was calculated at $343 \mathrm{~K}$, that is, $1.773 \times 10^{-10} \mathrm{~cm}^{2} / \mathrm{s}$. The Al coating was obtained on the surface of the AZ31 magnesium alloy electrode under appropriate conditions. According to the surface morphology of the $\mathrm{Al} \mathrm{film,} \mathrm{it} \mathrm{could} \mathrm{be} \mathrm{inferred} \mathrm{that} \mathrm{the} \mathrm{theoretical} \mathrm{deposit} \mathrm{thickness} \mathrm{is} \mathrm{similar} \mathrm{to}$ the actual thickness, and the apparent diffusion rate of $\mathrm{Al}$ ions is slower than the diffusion coefficient in the electrolytes. So, in the later deposition, lamellar $\mathrm{Al}$ along the diffusion direction were formed, and lamellar depleted $\mathrm{Al}$ zones existed around the big grain Al-rich region.
\end{abstract}

Keywords: electrodeposition; $\mathrm{Al}$; DES; nucleation; Mg alloys; diffusion

\section{Introduction}

Magnesium alloy is one of the lightest metal materials in industrial applications at present. It has the advantages of low density, high specific intensity, good machinability, low casting cost, and abundant resources [1]. Therefore, it is widely used in aerospace, automobile manufacturing, high-speed rail, and other fields [2-4]. However, its application in the industry is limited to a certain extent due to poor corrosion resistance [5]. Surface treatments such as anodization [6-8], electroless plating nickel [9,10], organic coating [11,12], and electrodeposition [13-15] are frequently applied to deal with the problems. One of the promising surface treatment methods is electrodeposition. It is generally known that Al is widely used as a surface coating owing to its excellent corrosion resistance, decorativeness, and physicochemical properties [16-18]. However, Al cannot be electrodeposited in an aqueous solution due to its large negative standard potential of $\mathrm{Al}(\mathrm{III}) / \mathrm{Al}$ couple ( $-1.67 \mathrm{~V}$ vs. NHE). Hence, the key step of deposited Al onto Mg alloys is finding a non-aqueous system.

Electrodeposition of $\mathrm{Al}$ in ionic liquids has received significant attention since Hurley and Wier reported that Al could be electrodeposited from ionic liquids [19]. It has been demonstrated that some typical examples of ionic liquids are suitable electrolytes to electrodeposit Al layer including aluminum chloride-1-ethyl-3-methylimidazolium chloride $\left(\mathrm{AlCl}_{3}\right.$-[EMIm]Cl) [20-22], aluminum chloride-trimethylphenylammonum chloride $\left(\mathrm{AlCl}_{3}-\right.$ TMPAC) [23,24], and aluminum chloride-n-butylpyridinium chloride $\left(\mathrm{AlCl}_{3}-\mathrm{BPC}\right)$ [25] Chang et al. [26] electrodeposited dense and bonded aluminum layers on magnesium alloys and improved the corrosion resistance of magnesium alloys significantly. Jiang et al. [23] 
obtained the aluminum coating on $\mathrm{W}$ by depositing in 2:1 $\mathrm{AlCl}_{3}$-TMPAC ionic liquid, analyzed the deposition of aluminum, which is controlled by instantaneous nucleation and diffusion.

However, ionic liquids are expensive and unsuitable for industrial production. Abbott et al. [27] reported new ionic liquids, called deep eutectic solvents (DES). DES are non-aqueous mixture solvents, which have a low freezing point because of the hydrogen bonding. The DES can exist in air and water stably. Most previous works have focused on the effect of coating on the corrosion resistance of the matrix. However, there are a few studies on the nucleation and growth kinetic model of metal ions on different electrodes ( $W$, glassy carbon, stainless steel) [28,29]. The nucleation and growth kinetic study of $\mathrm{Al}$ ions on magnesium alloy is minimal. Accordingly, the ionic liquids (DES) wer employed in this study, electrodeposition of $\mathrm{Al}$ on $\mathrm{AZ} 31 \mathrm{Mg}$ alloy was conducted, the nucleation and growth mechanism of $\mathrm{Al}$ on electrode were discussed, and diffusion coefficients of $\mathrm{Al}$ ions in DES ionic liquids and the apparent diffusion rate of $\mathrm{Al}$ atoms were calculated respectively.

\section{Materials and Methods}

Choline-chloride ( $\mathrm{ChCl}, 99 \%)$ and urea $(99 \%)$ were dried overnight at $333 \mathrm{~K}$ in advance. Aluminum chloride $\left(\mathrm{AlCl}_{3} \cdot 6 \mathrm{H}_{2} \mathrm{O}\right)$ was used as obtained. The DES was prepared by mixing $\mathrm{ChCl}(139.62 \mathrm{~g})$ with urea (120.12 g) hydrogen bond donor and the two components were heated at $353 \mathrm{~K}$ until a homogeneous colorless liquid was formed. Adjusting the $\mathrm{pH}$ values by $\mathrm{HCl}(4 \mathrm{~mol} / \mathrm{L})$ until the $\mathrm{pH}$ value was 5.8 . The deposition electrolytes were formed by slowly adding $\mathrm{AlCl}_{3} \cdot 6 \mathrm{H}_{2} \mathrm{O}(15.16 \mathrm{~g})$ to the $\mathrm{ChCl}$-urea DES [28,29]. Then the mixture was agitated for $10 \mathrm{~min}$ at $343 \mathrm{~K}$, until homogeneous electrolytes were obtained.

All the electrochemical experiments, including cyclic voltammetry $(\mathrm{CV})$ and chronoamperometry, were carried out on an electrochemical workstation (CS310) (Corrtest, Wuhan, China) in a three-electrode system. The working, counter, and reference electrodes were $\mathrm{Pt}$ (the total exposed surface area was about $0.25 \mathrm{~cm}^{2}$ ), Al plate, and $\mathrm{Al}$ wire, respectively. The distance between the tip of the reference electrode and working electrode was controlled between 1 and $1.5 \mathrm{~mm}$.

The diecast AZ31 Mg alloy, containing 3.05 wt.\% Al and $0.92 \mathrm{wt} . \% \mathrm{Zn}$, was used as the substrate in the study. The constant current deposition was performed on the AZ31 $\mathrm{Mg}$ alloy electrode in the two-electrode configuration. The deposition current density applied was $1 \mathrm{~mA} / \mathrm{cm}^{2}$. The electrode exposed area was $0.25 \mathrm{~cm}^{2}$ and the other portion sealed with epoxy resin. The Al plate (the exposed surface area was $2 \mathrm{~cm}^{2}$ ) was used as a cathode. Prior to electrodeposition, the electrodes were polished with sandpaper. The distance between the anode and cathode was about $20 \mathrm{~mm}$. The scanning electron microscopy (SEM, FEI Quanta250, FEI Company, Hillsborough, OR, USA) with EDS was employed to observe and analyze the surface morphology of the Al coating. The grain size of the surface was measured by Nano Measure software (Nano Measure 1.2, Fudan University, Shanghai, China).

\section{Results and Discussion}

By testing the cyclic voltammetry and chronoamperometry, the kinetics of nucleation/growth process was studied, the diffusion coefficient $\left(D_{v}\right)$ of $\mathrm{Al}$ was calculated, and according to the growth model of Al/AZ31 in DES, the differences of deposited thickness between theory value and experimental value were discussed.

\subsection{Control Link of Growth Process}

Cyclic voltammetry was used to qualitatively evaluate the $\mathrm{Al}$ electrodeposition onto the substrate. Figure 1 shows the cyclic voltammogram of the Pt electrode that was obtained in the DES ionic liquids with $\mathrm{AlCl}_{3}$. The voltammogram was obtained at a scan rate of $0.02 \mathrm{~V} / \mathrm{s}$ at a temperature of $343 \mathrm{~K}$. On the forward scan, there is a cathodic peak at approximately $0.03 \mathrm{~V}$ corresponding to $\mathrm{Al}$ deposition was formed. The anodic loop in reverse scan is about $0.7 \mathrm{~V}$ associated with the dissolution of $\mathrm{Al}$. 


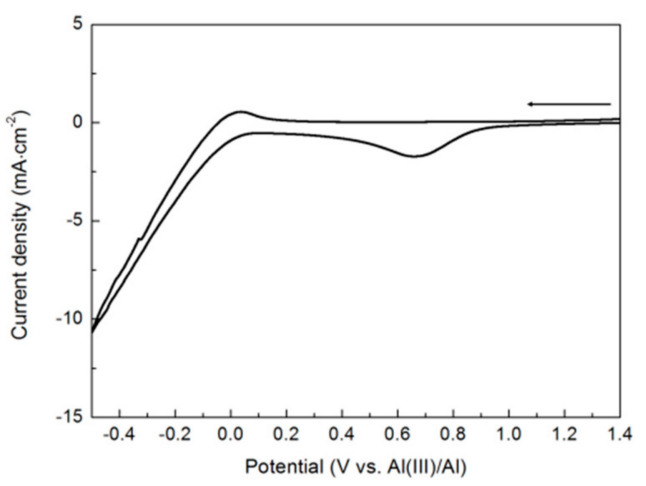

Figure 1. Cyclic voltammetry (CV) curves were recorded in DES- $\mathrm{AlCl}_{3}$ at $343 \mathrm{~K}$. Scan rate: $0.02 \mathrm{~V} / \mathrm{s}$, scan range: -0.5 to $1.4 \mathrm{~V}$.

Figure 2a shows a series of cyclic voltammograms on Pt electrode in $\mathrm{DES}-\mathrm{AlCl}_{3}$ ionic liquids at $343 \mathrm{~K}$. The scan rate was changed between 20 and $200 \mathrm{mV} / \mathrm{s}$. The peak current increased with the increases in scan rate. Figure $2 b$ shows that the peak current density $\left(i_{p c}\right)$ against the square root of scan rate $(L)$ exhibited good linearity. It can be inferred that the electrodeposition of $\mathrm{Al}$ from $\mathrm{DES}-\mathrm{AlCl}_{3}$ is a diffusion-controlled process. It is similar to some of the same types of work [28-30].

(a)

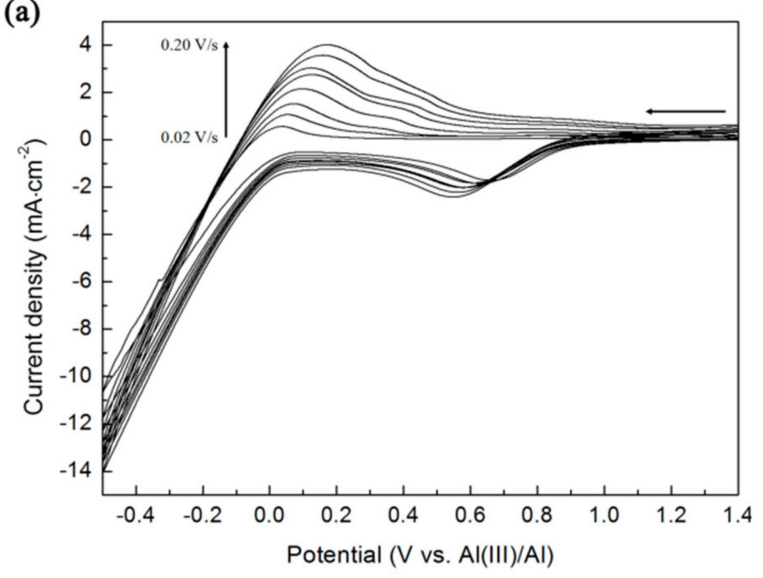

(b)

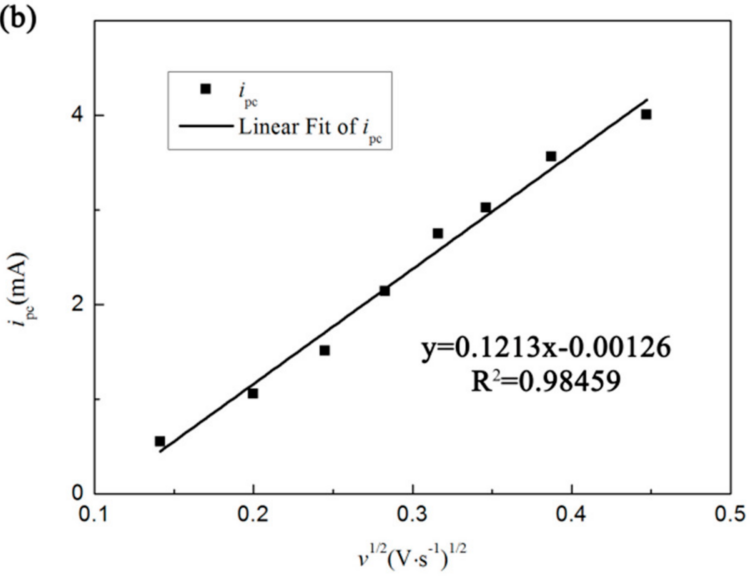

Figure 2. (a) A series of cyclic voltammograms recorded in $\mathrm{DES}-\mathrm{AlCl}_{3}$ with different scan rate. Scan range: -0.5 to $1.4 \mathrm{~V}$, (b) Relationship between the peak current $\left(D_{v}\right)$ and the square root of scan rate.

According to these plots, the diffusion coefficient of $\mathrm{Al}^{3+}\left(D_{v}\right)$ can be calculated using the Berzins-Delahay equation (Equation (1)) [31],

$$
i_{p}=0.61(z F)^{\frac{3}{2}}(R T)^{-\frac{1}{2}} A D_{v^{\frac{1}{2}}} c v^{\frac{1}{2}}
$$

where $i_{p}$ is the cathodic peak current $(\mathrm{A}), c$ is the bulk concentration of the reactant $\left(\mathrm{mol} / \mathrm{cm}^{3}\right), A$ is the area of the electrode $\left(\mathrm{cm}^{2}\right), z$ is the number of electrons, $v$ is the potential sweep rate $(\mathrm{V} / \mathrm{s}), F$ is the Faraday constant $(\mathrm{C} / \mathrm{mol}), R$ is the gas constant $(\mathrm{J} / \mathrm{mol} \cdot \mathrm{K}), T$ is the absolute temperature $(\mathrm{K})$.

The cyclic voltammograms were tested in DES- $\mathrm{AlCl}_{3}$ ionic liquids by changing the scan rate from 20 to $200 \mathrm{mV} / \mathrm{s}$, and obtained the peak current densities $\left(i_{p}\right)$ at different scan rates $(v)$. According to the literature $[28,29]$, when the peak current density $\left(i_{p}\right)$ against the square root of scan rate $\left(v^{1 / 2}\right)$ exhibited linearity (Figure $2 b$ ), the restriction factor of electrodeposition was the diffusion of $\mathrm{Al}$ in DES. Table 1 depicts the diffusion coefficient of $\mathrm{Al}$ ions at $343 \mathrm{~K}$, calculated by Equation (1). The diffusion coefficient $\left(D_{v}\right)$ of $\mathrm{Al} / \mathrm{AZ3} 1$ in DES was $1.773 \times 10^{-10} \mathrm{~cm}^{2} / \mathrm{s}$ in this paper. In the literature $[28,29]$, the diffusion 
coefficient $\left(D_{v}\right)$ of $\mathrm{Cu} / \mathrm{Ni}(303 \mathrm{~K})$ and $\mathrm{Pt} / \mathrm{Ti}$ (room temperature) in DES was $9.78 \times 10^{-8}$ and $2.13 \times 10^{-6}$, respectively.

Table 1. The calculated diffusion coefficient of $\mathrm{Al}$ ions at $343 \mathrm{~K}$.

\begin{tabular}{cccc}
\hline Solution & Ion & $\boldsymbol{i}_{\boldsymbol{p}}(\mathrm{A})$ & $\boldsymbol{D}_{\boldsymbol{v}}\left(\mathbf{c m}^{2} / \mathbf{s}\right)$ \\
\hline $\mathrm{DES}-\mathrm{AlCl}_{3}$ & $\mathrm{Al}^{3+}$ & $5.55 \times 10^{-4}$ & $1.773 \times 10^{-10}$ \\
\hline
\end{tabular}

\subsection{Nucleation Pattern of $A l$}

Chronoamperometry was used to investigate the nucleation and growth process of $\mathrm{Al}$ electrodeposition on a Pt electrode in $\mathrm{DES}-\mathrm{AlCl}_{3}$ ionic liquids. A series of current-time curves with different step potentials for the electrodeposition of $\mathrm{Al}$ in $\mathrm{DES}-\mathrm{AlCl}_{3}$ ionic liquids at $343 \mathrm{~K}$ are shown in Figure 3.

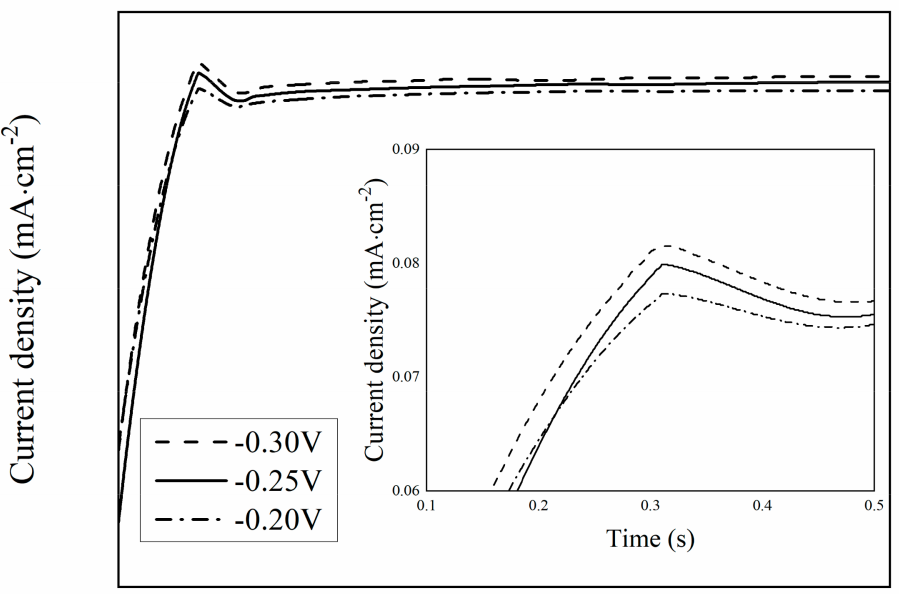

Time (s)

Figure 3. Current-time transients of the chronoamperometric experiments in DES with various potentials. Inset: the corresponding high-magnification image.

These curves initially show a rapid upward trend due to the formation and growth of the aluminum core on the electrode surface. The rising current eventually reaches its maximum $\left(i_{m}\right)$ at time $\left(t_{m}\right)$, when the individual diffusion areas of the crystal begin to overlap [32]. Subsequently, the current curves decay as the deposited layer becomes thicker. With the applied potential being more negative, the time reached to $i_{m}$ is shortened (from inset of Figure 3).

The hemispherical diffusion model, summarized by Allongue and Souteyrand, was the three-dimensional nucleation and growth process of metal ions. It is another type of Sharifker-Hills model, which was suitable for the process of diffusion-controlled nucleation and growth [32]. According to Figure 2, the restriction factor of electrodeposition is the diffusion of Al. So the hemispherical diffusion model was selected to explain the nucleation and growth process. This model has two limiting cases: instantaneous nucleation Equation (2) and progressive nucleation Equation (3) [33]. They are expressed respectively by

$$
\begin{gathered}
\left(i / i_{m}\right)^{2}=1.9542\left(t / t_{m}\right)^{-1}\left\{1-\exp \left[-1.2564\left(t / t_{m}\right)\right]\right\}^{2} \\
\left(i / i_{m}\right)^{2}=1.2254\left(t / t_{m}\right)^{-1}\left\{1-\exp \left[-2.3367\left(t / t_{m}\right)^{2}\right]\right\}^{2}
\end{gathered}
$$

In Equations (2) and (3), a correction $t_{0}$ must be made by refining the $t^{\prime}=t-t_{0}$ and $t^{\prime}{ }_{m}=t_{m}-t_{0}$. The $t_{0}$ could be obtained from the intercept of plots of $\left(i / i_{m}\right)^{2}$ vs. $t$. 
The dimensionless theoretical plots resulting from Equations (2) and (3), and experimental data are shown in Figure 4.

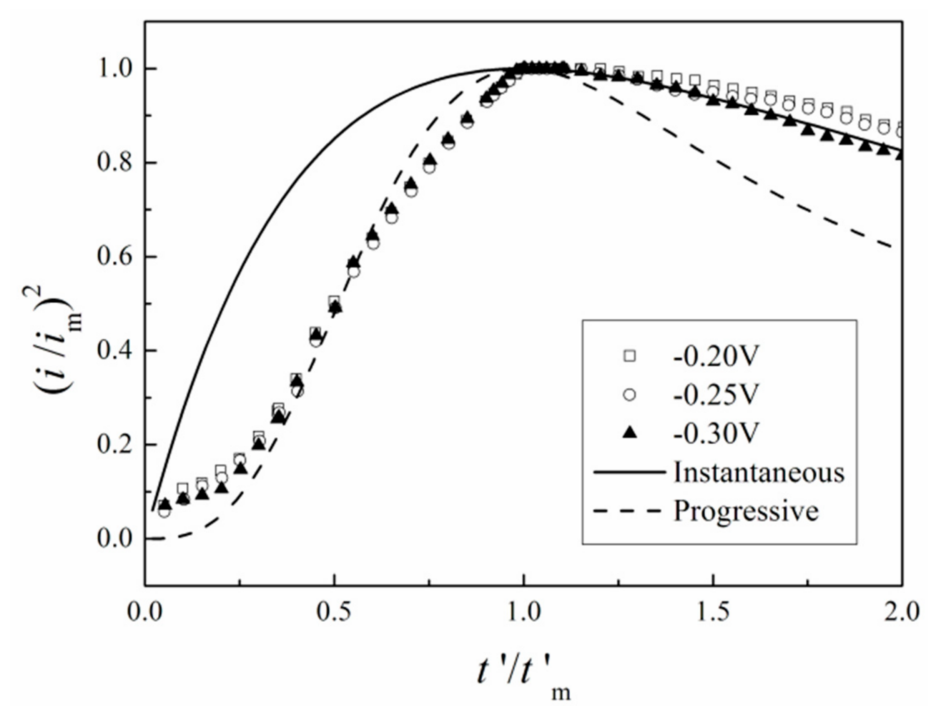

Figure 4. Comparison of the experimental data with the theoretical models for three-dimensional instantaneous and progressive nucleation.

Figure 4 exhibits a typical form of three-dimensional diffusion-controlled nucleation and growth process. In short times, the nucleation mechanism fits quite well to that of a progressive growth process (dotted curve in Figure 4). However, at times beyond the current maximum, $\left(i / i_{m}\right)$, the experimental data do not fit well to the progressive growth process. It exhibits instantaneous nucleation character (full line in Figure 4). It means the nucleation/growth of $\mathrm{Al}$ on AZ31 conformed to the hemispherical diffusion model: progressive nucleation in the early phases and instantaneous nucleation after current maxima.

\subsection{The Nucleation and Growth Process of Al Deposits}

According to the hemispherical diffusion model, the nucleation and growth of $\mathrm{Al}$ on the substrate was a three-dimensional process. To validate this process, the surface morphology of $\mathrm{Al}$ deposits were observed, and the theory/experimental value of deposit thickness was calculated.

\subsubsection{Surface Morphology and Nucleation/Growth Model of Al Deposits}

The distribution of deposits was obtained by scanning electron microscopy (SEM). Figure 5 shows the surface morphology of Al particles electrodeposited on AZ31 Mg alloys. As shown in Figure 5, the film and grain are formed on the substrate surface. Besides, the analysis of EDS revealed that the deposits were $\mathrm{Al}_{2} \mathrm{O}_{3}$, which may improve the corrosion resistance of magnesium alloy substrate. As Figure $5 b^{\prime}, c^{\prime}$, with the deposition time rises (from $1 \mathrm{~h}$ to $3 \mathrm{~h}$ ), Al particles in different locations start diffusing stacked (Figure 5b'). Lamellar $\mathrm{Al}$ along the direction of diffusion was formed (Figure $5 \mathrm{c}^{\prime}$ ); as a result, there existed lamellar depleted $\mathrm{Al}$ zones around the big grain $\mathrm{Al}$-rich region. It means that the deposition of $\mathrm{Al}$ on $\mathrm{Mg}$ alloys electrode abides by the following rules: the initial stage is progressive nucleation, and the later stage is instantaneous nucleation. It is consistent with the result of chronoamperometry (Figure 4). 

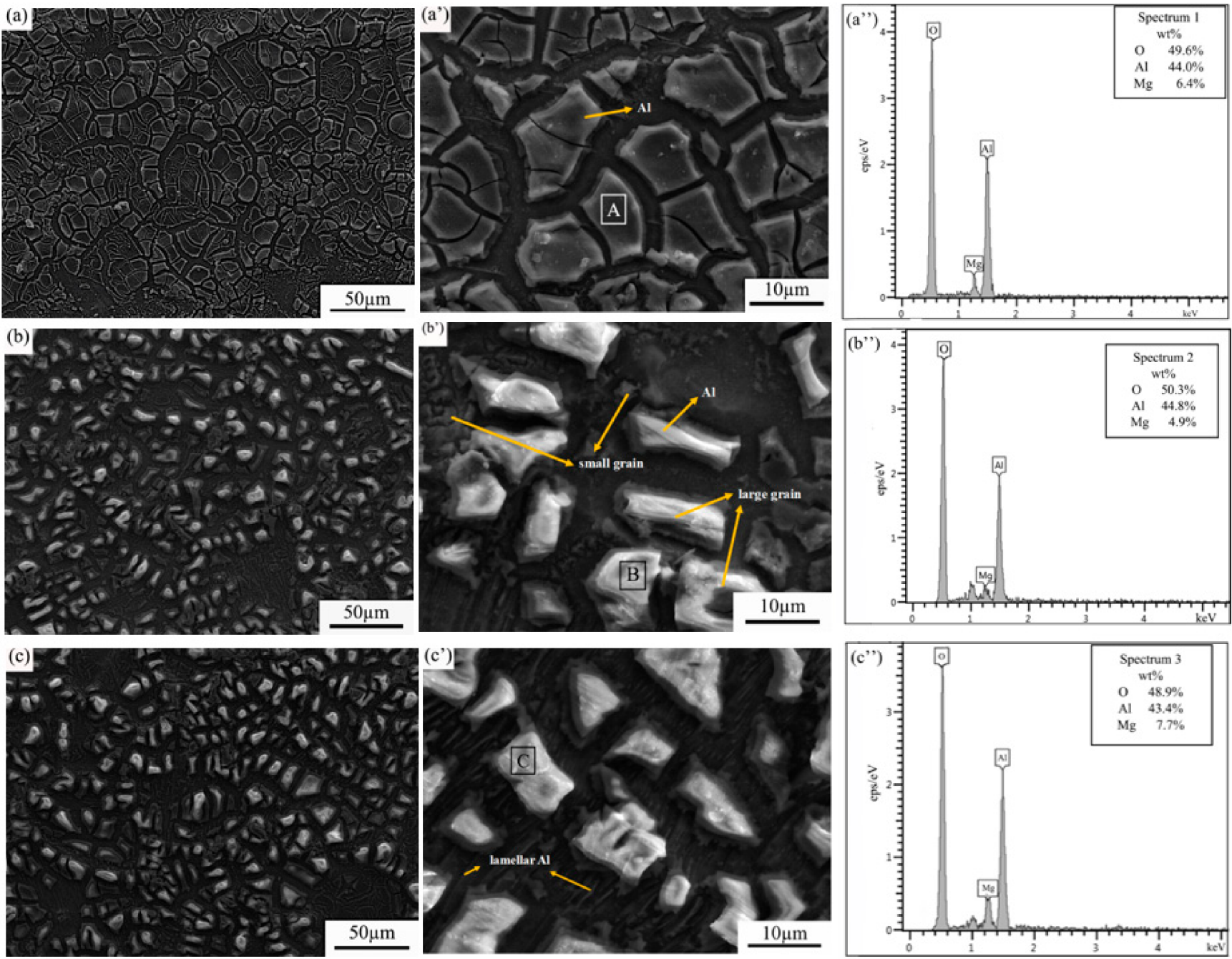

Figure 5. The morphology of Al particles electrodeposited on AZ31 with different times (a) $1 \mathrm{~h},(\mathbf{b}) 2 \mathrm{~h},(\mathbf{c}) 3 \mathrm{~h}$, (a') enlarged view of $(\mathbf{a}),\left(\mathbf{b}^{\prime}\right)$ enlarged view of $(\mathbf{b}),\left(\mathbf{c}^{\prime}\right)$ enlarged view of $(\mathbf{c}),\left(\mathbf{a}^{\prime \prime}\right)$, EDS of area A in $\left(\mathbf{a}^{\prime}\right),\left(\mathbf{b}^{\prime \prime}\right)$ EDS of area B in $\left(\mathbf{b}^{\prime}\right),\left(\mathbf{c}^{\prime \prime}\right)$ EDS of area $\mathrm{C}$ in $\left(\mathbf{c}^{\prime}\right)$.

Figure 6 is a model diagram of nucleation and growth. First, the $\mathrm{Al}$ ions in the electrolytes are diffused from the solution to electrolytes and electrode interface. Based on previous calculations, the diffusion coefficient of $\mathrm{Al}$ ions is $1.773 \times 10^{-10} \mathrm{~cm}^{2} / \mathrm{s}$. Then, the $\mathrm{Al}$ ions reached the electrode at the active sites, nucleated on the surface of the electrode at the same time. The growth of nuclei includes two directions: planar growth and vertical growth. At the early growth stage, the planar growth is dominated (Figure 6a). Finally, the nucleus decreased with the increase in deposition time (Figure $6 b, c)$. With the deposition decreased, the growth rate is slowing down gradually. So, $\mathrm{Al}$ ions are stacked up by hemispherical models, and the Al particles of the electrode surface are diffusing stacked at the same time. At the later stage of deposition, coating continues to grow. Meanwhile, the nucleation process does not exist. It is the reason for the grains size decreasing, as shown in Table 2. This nucleation and growth process is similar to the Al depositing on stainless steel [18], but the diffusion coefficient of Al/AZ31 $\left(1.773 \times 10^{-10} \mathrm{~cm}^{2} / \mathrm{s}\right)$ is lower than $\mathrm{Al} /$ stainless steel $\left(1.20 \times 10^{-8} \mathrm{~cm}^{2} / \mathrm{s}\right)$. 


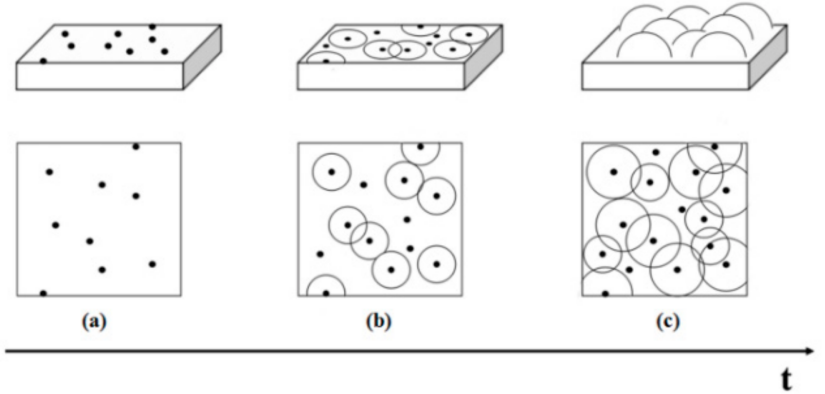

Figure 6. The model diagram of nucleation/growth.

Table 2. The image data of deposits surface from Figure 5.

\begin{tabular}{cccc}
\hline Deposition time, $\boldsymbol{t}(\mathbf{h})$ & $\mathbf{1}$ & $\mathbf{2}$ & $\mathbf{3}$ \\
\hline Average grain size, $L(\mathrm{~cm})$ & $8.48 \times 10^{-4}$ & $7.14 \times 10^{-4}$ & $7.88 \times 10^{-4}$ \\
\hline
\end{tabular}

\subsubsection{Deposit Thickness}

It is assumed that the growth of $\mathrm{Al}$ follows a hemispherical growth model, and the $\mathrm{Al}$ nuclei uniformly distribute on the substrate surface randomly.

Some experimental data of the surface are shown in Table 2 from Figure 5.

According to above data, the theoretical deposit thickness of the initial stage $(1 \mathrm{~h})$, $d_{\text {theo. }}(\mathrm{cm})$, was calculated as follows:

$$
Q=I t=F n z
$$

where,

$$
\begin{aligned}
& n=\frac{\rho A d}{M} \\
& I=i S_{\text {wire }}
\end{aligned}
$$

where $I$ is the current of flowing through a wire per unit time (A); $t$ is the deposition time (s); $F$ is the Faraday constant $(\mathrm{C} / \mathrm{mol}) ; n$ is the theoretical deposits moles (mol); $z$ is the number of electrons; $\rho$ is the deposits density $\left(\mathrm{g} / \mathrm{cm}^{3}\right) ; A$ is the area of electrode $\left(\mathrm{cm}^{2}\right) ; M$ is the molar mass of deposits $(\mathrm{g} / \mathrm{mol}) ; i$ is the current density $\left(\mathrm{A} / \mathrm{cm}^{2}\right) ; S_{\text {wire }}$ is the cross-sectional area of the wire $\left(\mathrm{cm}^{2}\right)$.

Equation (7) can be obtained from the Equations (4)-(6). It shows the relationship between theoretical deposits thickness $\left(d_{\text {theo. }}\right)$ and deposition time $(t)$,

$$
d_{\text {theo. }}=\frac{M I t}{A \rho F a}
$$

The initial stage $(1 \mathrm{~h})$ theoretical deposits thickness $d_{\text {theo. }}$ is $3.5 \times 10^{-5} \mathrm{~cm}$ from Equation (7).

On the basis of the image data of the deposit's surface, the actual deposition area,

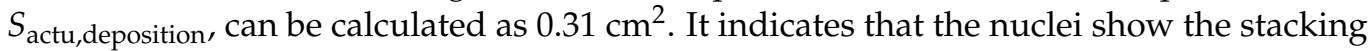
phenomenon.

Based on the conservation of mass, it can be inferred that the $d_{\text {actu. value is }}$ $2.7 \times 10^{-5} \mathrm{~cm}$, which is near to the result $\left(3.5 \times 10^{-5} \mathrm{~cm}\right)$ from Equation (7). The theory value and experimental data are an order of magnitude. As the electrodeposition going on, the concentration of electrolyte becomes lower, and the current density becomes uneven [28]. The changing of these factors causes the experimental data is thinner than the theoretical value. 


\subsubsection{Kinetic Diffusion Coefficients}

Assuming that the initial stage $(1 \mathrm{~h})$ of the nucleation rate on the electrode surface is equal to the diffusion coefficient in the electrolytes $\left(v=D_{v}=1.773 \times 10^{-10} \mathrm{~cm}^{2} / \mathrm{s}\right)$. Nuclei radius, $\frac{L}{2}$, is described as a function of diffusion coefficient $v$ by the relation [33]:

$$
\frac{L}{2}=k \sqrt{v t}
$$

$k$ is a numerical constant and always remains constant throughout the deposition process. According to Equation (8), the $k$ is calculated as 0.53 .

According to Equation (8) and the average grain size in Table 1, the apparent diffusion rate of $2 \mathrm{~h}$ and $3 \mathrm{~h}$ can be calculated, respectively. They are $6.3 \times 10^{-11} \mathrm{~cm}^{2} / \mathrm{s}$ and $5.1 \times 10^{-11} \mathrm{~cm}^{2} / \mathrm{s}$. They are both smaller than the diffusion coefficient in the electrolytes $D_{v}$. It indicates that the apparent diffusion rate is a consequence of the ions diffusion in the electrolytes and the diffusion of the atoms on the electrode.

\section{Conclusions}

The nucleation and growth kinetics behavior of $\mathrm{Al}$ were discussed in the $\mathrm{AlCl}_{3}-\mathrm{ChCl}-$ urea DES. The voltammetric studies demonstrated that $\mathrm{Al}$ electrodeposition involves a diffusion-controlled process. The diffusion coefficient of $\mathrm{Al}$ ions was calculated at $343 \mathrm{~K}$, which is $1.773 \times 10^{-10} \mathrm{~cm}^{2} / \mathrm{s}$. The analysis of chronoamperometry indicates that the initial stage of electrodeposition corresponds to three-dimensional progressive nucleation and the later stage is instantaneous nucleation. By the constant current deposition experiment, the metallic $\mathrm{Al}$ layer was obtained onto $\mathrm{AZ} 31 \mathrm{Mg}$ alloys successfully in the $\mathrm{ChCl}$-urea DES ionic liquids. The theoretical deposit thickness $\left(3.5 \times 10^{-5} \mathrm{~cm}\right)$ is similar to the actual thickness $\left(2.7 \times 10^{-5} \mathrm{~cm}\right)$. Because the apparent diffusion rate depends on the ions diffusion in the electrolytes and the diffusion of the atoms on the electrode, the apparent diffusion rate is smaller than diffusion coefficient in the electrolytes.

Author Contributions: Conceptualization, J.Z. and X.Z.; methodology, X.Z. and Y.L.; validation, Y.L., J.Z., and X.Z.; formal analysis, Y.L.; investigation, Y.L.; data curation, J.Z.; writing—original draft preparation, Y.L.; writing - review and editing, J.Z. and X.Z.; supervision, Y.Y. and S.W.; project administration, J.Z. All authors have read and agreed to the published version of the manuscript.

Funding: This research was funded by the National Natural Science Foundation of China (No. 52004180), Shanxi Province Science Foundation (No.201801D221138).

Institutional Review Board Statement: Not applicable.

Informed Consent Statement: Not applicable.

Data Availability Statement: Data sharing is not applicable to this article.

Acknowledgments: This research was supported by the National Natural Science Foundation of China (No. 52004180), Shanxi Province Science Foundation (No.201801D221138).

Conflicts of Interest: The authors declare no conflict of interest.

\section{References}

1. Pan, F.S.; Yang, M.B.; Chen, X.H. A Review on Casting Magnesium Alloys: Modification of Commercial Alloys and Development of New Alloys. J. Mater. Sci. Technol. 2016, 32, 1211-1221. [CrossRef]

2. Mordike, B.L.; Ebert, T. Magnesium: Properties-Applications-Potential. Mat. Sci. Eng. A Struct. 2001, 302, 37-45. [CrossRef]

3. Zhang, J.L.; Liu, Y.L.; Liu, J.; Yu, Y.C.; Wang, S.B. The effect of Gd element and solution treatment on the microstructure of AZ31 magnesium alloy and its kinetic model. J. Alloy. Compd. 2016, 663, 610-616. [CrossRef]

4. Xu, R.Z.; Ni, D.R.; Yang, Q.; Liu, C.Z.; Ma, Z.Y. Pinless Friction Stir Spot Welding of Mg-3Al-1Zn Alloy with Zn Interlayer. J. Mater. Sci. Technol. 2016, 32, 76-88. [CrossRef]

5. Wang, B.J; Wang, S.D.; Xu, D.K.; Han, E.H. Recent progress in fatigue behavior of Mg alloys in air and aqueous media: A review. J. Mater. Sci. Technol. 2017, 33, 1075-1086. [CrossRef]

6. Hsiao, H.Y.; Tsung, H.C.; Tsai, W.T. Anodization of AZ91D magnesium alloy in silicate-containing electrolytes. Surf. Coat. Technol. 2005, 199, 127-134. [CrossRef] 
7. Wu, H.L.; Cheng, Y.L.; Li, L.L.; Chen, Z.H.; Wang, H.M.; Zhang, Z. The anodization of ZK60 magnesium alloy in alkaline solution containing silicate and the corrosion properties of the anodized films. Appl. Surf. Sci. 2007, 253, 9387-9394. [CrossRef]

8. Yang, Y.C.; Xia, Y.; Huang, W.; Zheng, J.F.; Li, Z.L. Fabrication of nano-network gold films via anodization of gold electrode and their application in SERS. J. Solid State Electr. 2012, 16, 1733-1739. [CrossRef]

9. Mao, Y.; Li, Z.G.; Feng, K.; Guo, X.W.; Zhou, Z.F.; Wu, Y.X. Corrosion behavior of carbon film coated magnesium alloy with electroless plating nickel interlayer. J. Mater. Process. Technol. 2015, 219, 42-47. [CrossRef]

10. Tzeng, G.-S. Effect of halide ions on electroless nickel plating. J. Appl. Electrochem. 1995, 26, 969-975. [CrossRef]

11. Chen, X.M.; Li, G.Y.; Lian, J.S.; Jiang, Q. An organic chromium-free conversion coating on AZ91D magnesium alloy. Appl. Surf. Sci. 2008, 255, 2322-2328. [CrossRef]

12. Gelling, V.J.; Wiest, M.M.; Tallman, D.E.; Bierwagen, G.P.; Wallace, G.G. Electroactive-conducting polymers for corrosion control 4. Studies of poly(3-octyl pyrrole) and poly(3-octadecyl pyrrole) on aluminum 2024-T3 alloy. Prog. Org. Coat. 2001, 43, 149-157. [CrossRef]

13. Liu, Q.; Chen, D.X.; Kang, Z.X. One-Step Electrodeposition process to fabricate corrosion-resistant superhydrophobic surface on magnesium alloy. ACS Appl. Mater. Interfaces 2015, 7, 1859-1867. [CrossRef] [PubMed]

14. Song, Y.W.; Shan, D.Y.; Han, E.H. Electrodeposition of hydroxyapatite coating on AZ91D magnesium alloy for biomaterial application. Mater. Lett. 2008, 62, 3276-3279. [CrossRef]

15. Xu, C.Y.; Hua, Y.X.; Zhang, Q.B.; Li, J.; Lei, Z.; Lu, D.H. Electrodeposition of Al-Ti alloy on mild steel from AlCl3-BMIC ionic liquid. J. Solid State Electr. 2017, 21, 1349-1356. [CrossRef]

16. Zhang, Q.Q.; Wang, Q.; Zhang, S.J.; Lu, X.M. Effect of nicotinamide on electrodeposition of Al from aluminium chloride (AlCl3)-1-butyl-3-methylimidazolium chloride ([Bmim]Cl) ionic liquids. J. Solid State Electr. 2014, 18, 257-267. [CrossRef]

17. Song, G.L. Corrosion and protection of magnesium alloys: An overview of research undertaken by CAST. Mater. Sci. Forum 2005, 488-489, 649-652. [CrossRef]

18. Yue, G.K.; Zhang, S.J.; Zhu, Y.L.; Lu, X.M.; Li, S.C.; Li, Z.X. A promising method for electrodeposition of aluminium on stainless Steel in ionic liquid. AIChE J. 2009, 55, 783-796. [CrossRef]

19. Hurley, F.H.; Wier, T.P. Electrodeposition of Metals from Fused Quaternary Ammonium Salts. J. Electrochem. Soc. 1951, 98, 203-206. [CrossRef]

20. Chang, J.K.; Sun, I.W.; Pan, S.J.; Chuang, M.H.; Deng, M.J.; Tsai, W.T. Electrodeposition of Al coating on Mg alloy from Al chloride/1-ethyl-3-methylimidazolium chloride ionic liquids with different Lewis acidity. Trans. IMF 2008, 86, 227-233. [CrossRef]

21. Yang, H.Y.; Guo, X.W.; Wu, G.H.; Ding, W.J.; Birbilis, N. Electrodeposition of chemically and mechanically protective Al-coatings on AZ91D Mg alloy. Corros. Sci. 2011, 53, 381-387. [CrossRef]

22. Tsuda, T.; Kuwabata, S.; Stafford, G.R.; Hussey, C.L. Electrodeposition of aluminum-hafnium alloy from the Lewis acidic aluminum chloride-1-ethyl-3-methylimidazolium chloride molten salt. J. Solid State Electr. 2013, 17, 409-417. [CrossRef]

23. Jiang, T.; Brym, M.J.C.; Dube, G.; Lasia, A.; Brisard, G.M. Electrodeposition of aluminium from ionic liquids: Part II - studies on the electrodeposition of aluminum from aluminum chloride (AICl(3))-trimethylphenylammonium chloride (TMPAC) ionic liquids. Surf. Coat. Technol. 2006, 201, 10-18. [CrossRef]

24. Liu, K.R.; Liu, Q.; Han, Q.; Tu, G.F. Electrodeposition of Al on AZ31 magnesium alloy in TMPAC-AlCl3 ionic liquids. Trans. Nonferrous Met. Soc. China 2011, 21, 2104-2110. [CrossRef]

25. Ali, M.R.; Nishikata, A.; Tsuru, T. Electrodeposition of Al-Ni intermetallic compounds from aluminum chloride-N-(nbutyl)pyridinium chloride room temperature molten salt. J. Electroanal. Chem. 2001, 513, 111-118. [CrossRef]

26. Chang, J.K.; Chen, S.Y.; Tsai, W.T.; Deng, M.J.; Sun, I.W. Electrodeposition of aluminum on magnesium alloy in aluminum chloride $\left(\mathrm{AlCl}_{3}\right)$-1-ethyl-3-methylimidazolium chloride (EMIC) ionic liquid and its corrosion behavior. Electrochem. Commun. 2007, 9, 1602-1606. [CrossRef]

27. Abbott, A.P.; Capper, G.; Davies, D.L.; Rasheed, R.K.; Tambyrajah, V. Novel solvent properties of choline chloride/urea mixtures. Chem. Commun. 2003, 1, 70-71. [CrossRef]

28. Zhang, Q.B.; Hua, Y.X. Electrochemical synthesis of copper nanoparticles using cuprous oxide as a precursor in choline chlorideurea deep eutectic solvent: Nucleation and growth mechanism. Phys. Chem. Chem. Phys. 2014, 16, 27088-27095. [CrossRef]

29. Fuentes, A.S.; Filippin, A.F. Pd nucleation and growth mechanism deposited on different substrates. Procedia Mater. Sci. 2015, 8, 541-550. [CrossRef]

30. Zheng, Y.; Zhang, S.J.; Lu, X.M.; Wang, Q.; Zuo, Y.; Liu, L. Low-temperature Electrodeposition of Aluminium from Lewis Acidic 1-Allyl-3-methylimidazolium Chloroalluminate Ionic Liquids. Chin. J. Chem. Eng. 2012, 20, 130-139. [CrossRef]

31. Bard, A.J.; Faulker, L.R. Electrochemical Methods Fundamentals and Applications; John Wiley \& Sons Inc.: New York, NY, USA, 2001.

32. Xu, X.H.; Hussey, C.L. Electrodeposition of Silver on Metallic and Nonmetallic Electrodes from the Acidic Aluminum Chloride-1Methyl-3-Ethylimidazolium Chloride Molten Salt. J. Electrochem. Soc. 1992, 139, 1295-1300. [CrossRef]

33. Scharifker, B.; Hills, G. Theoretical and experimental studies of multiple nucleation. Electrochim. Acta 1983, 28, 879-889. [CrossRef] 